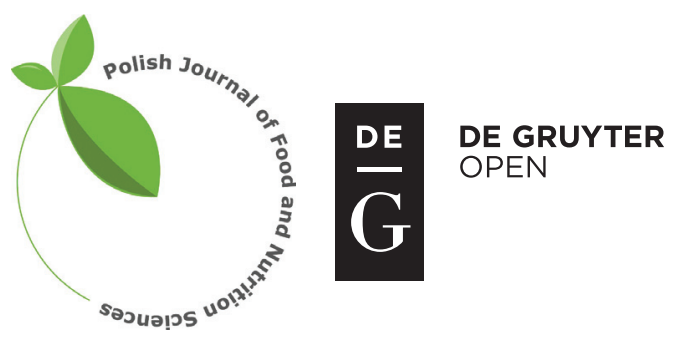

Pol. J. Food Nutr. Sci., 2016, Vol. 66, No. 1, pp. 37-41

DOI: $10.1515 /$ pjfns-2015-0056 http://journal.pan.olsztyn.pl

Original article

Section: Nutritional Research

\title{
An Inulin-Enriched Soy Drink and Its Lowering Effect on Oxidized Low Density Lipoproteins in Healthy Volunteers
}

\author{
Algirdas Liutkevičius ${ }^{1}$, Vilma Speičiene $\dot{e}^{* 1}$, Lina Vaičiulytè-Funk ${ }^{1}$, Aldona Mieželienè ${ }^{1}$, Gitana \\ Alenčikienè $^{1}$, Algis Abaravičius ${ }^{2}$, Loreta Bagdonaitè ${ }^{2}$, Valerija Jablonskienè ${ }^{2}$, Arvydas Kaminskas ${ }^{2}$
}

\author{
${ }^{1}$ Food Institute, Kaunas University of Technology, Kaunas, Lithuania \\ ${ }^{2}$ Department of Physiology, Biochemistry, Microbiology and Laboratory Medicine, \\ Medicine Faculty, Vilnius University, Vilnius, Lithuania
}

Key words: drink, soy protein isolate, prebiotic dietary fiber inulin, oxidized low density lipoproteins

Due to selection of appropriate ingredients and parameters, a microbiologically-safe drink enriched with soy protein isolate (SPI) and prebiotic dietary fiber inulin with high scores of acceptability was produced. The results of medical nutrition survey showed that on the 21 day of using drink the level of oxidized low density lipoproteins (LDL) significantly decreased while the other biochemical parameters of blood of healthy patients as compared to the control tests remained unchanged. As well there was no apparent impact on the intestinal microflora balance of recipients established.

\section{INTRODUCTION}

There is no doubt that proper and healthy nutrition helps to prevent a number of chronic non-communicable diseases and is one of the key determinants of good health and life quality [Lindeberg, 2013]. Recognizing the unique opportunity that exists to formulate and implement an effective strategy for substantial reduction of deaths and disease burden worldwide by improving diet and promoting physical activity, the World Health Organization (WHO) has adopted the "Global Strategy on Diet, Physical Activity and Health" in May 2004 [WHO, 2004].

Increasing knowledge of the relationship between diet and health leads to new insights into the effects of food ingredients on physiological functions and health. Despite the absence of a universally accepted definition on functional foods, there is a growing general agreement that some foods and drinks have beneficial effects beyond normal nutrition [Pang et al., 2012].

The SPI is the most refined soy protein product possessing many functional properties. Therefore it is used in a wide range of food applications, including processed meat, nutritional drinks, infant formulas, and dairy product replacements [Tsumura et al., 2005]. According to the protein digestibility, the corrected amino acid score (PDCAAS) comprises only few proteins, among them and soy protein has the highest PDCAAS score [Schaafsma, 2000]. Epidemiological investigations suggest that soy consumption may be associated with

\footnotetext{
* Corresponding Author: E-mail: vilma.speiciene@ktu.lt ety of the data, it seems that inulin is likely to have a beneficial

a lower incidence of certain chronic diseases. Clinical studies have also shown that ingestion of soy proteins reduces the risk factors for cardiovascular diseases. The Nutrition Committee of the American Heart Association has assessed 22 randomized trials conducted since 1999 and found that SPI with soy isoflavones (ISF) slightly decreased LDL-cholesterol [Xiao, 2008]. Soy protein consumption with a median of $30 \mathrm{~g} / \mathrm{d}$ was associated with a significant improvement in lipoprotein risk factors for coronary heart disease. Compared with crossover randomized controlled trials (RCT), parallel RCT had significantly higher quality grades and were associated with significantly greater improvements in serum LDL-cholesterol values.

The other studies show that the existing data are inconsistent or inadequate in supporting most of the suggested health benefits of consuming soy protein or ISF [Hoie et al., 2007; Thorp et al., 2008]. Finally, in 2012 the European Food Safety Authority (EFSA) Panel on Dietetic Products, Nutrition and Allergies concluded that a cause-and-effect relationship had not been established between the consumption of SPI and a reduction in blood LDL-cholesterol concentrations [EFSA, 2012].

The conclusion can be drawn that currently there is no final consensus on the effects of soy protein on human health parameters.

Several studies showed that inulin may act as a prebiotic and improve health by modulating the composition and metabolic activity of the intestinal microflora [Gibson, 1999; Kuntz et al., 2013]. But the results are controversial because of the differences in animal and human study models. Despite the vari- 
impact on health status, especially in cases of inflammation, infection and non-infectious diseases, during antibiotic and other drug consumption, constipation and other conditions when human intestinal microflora might be changed [Kleessen et al., 2007; Waitzberg et al., 2012; Paßlack et al., 2015].

The aim of the research was to design a technology of the functional drink enriched with SPI (4 g/100 g) and prebiotic dietary fiber inulin (2 g/100 g) and establish its influence on some metabolic parameters of healthy volunteers.

\section{MATERIALS AND METHODS}

\section{Materials}

SPI (SUPRO XT 219D IP) containing $87 \mathrm{~g}$ of proteins and $200 \mathrm{mg}$ isoflavones per $100 \mathrm{~g}$ was obtained from Vitex $\mathrm{Nu}$ trition Ltd. (Vancouver, Canada), inulin preparation (Orafti GR), containing more than $90 \%$ of inulin was obtained from BENEO (Tienen, Belgium), and pectin (Pectin 64017) was supplied by Cargill (Hamburg, Germany).

\section{Preparation of drink}

The drink formulation was as follows: SPI (4.0\%), inulin preparation $(2.0 \%)$, sugar $(5.7 \%)$, pectin $(0.4 \%)$, vanilla sugar $(1.0 \%)$, instant coffee $(0.2 \%)$, and tap water $(86.7 \%)$. All ingredients were solubilized in tap water $\left(60 \pm 2^{\circ} \mathrm{C}\right)$, homogenization was performed by using HP203-A inline high pressure homogenizer (OMVE, Schalkwijk, Netherlands) at $15 \mathrm{MPa}$, and followed by sterilization $\left(121^{\circ} \mathrm{C}\right.$ for $\left.12 \mathrm{~min}\right)$, cooling down (up to $20^{\circ} \mathrm{C}$ ), distribution into plastic bottles $(500 \mathrm{~mL})$ and storage $\left(4 \pm 2^{\circ} \mathrm{C}\right)$.

\section{Active acidity measurements}

Active acidity was determined by a microprocessor $538 \mathrm{pH}$ -meter, using an electrode with a Sen Tix 97 T integrated temperature sensor (WTW GmbH, Weilheim, Germany).

\section{Microbiological analysis}

The assessment of microbiological indicators was carried out on the first day and after 30 days of drinks storage. The total number of microorganisms was evaluated according to ISO 4833-1:2013, the number of coliform bacteria according to ISO 4832:2006, and the number of E.coli - according to ISO 16649-2:2001.

\section{Sensory analysis}

A preliminary acceptability $(n=12$, consumers aged 22-65) was evaluated by asking which sensory properties could negatively affect the acceptability. The samples for sensory analysis (approximately $20 \mathrm{~mL}, 21 \pm 2^{\circ} \mathrm{C}$ ) were provided to the consumer panel in $30 \mathrm{~mL}$ plastic cups, coded with three digital numbers. A structured numerical scale was used for the evaluation of the acceptability of each attribute. The left side of the scale corresponding to the "dislike extremely" was given the value of 1 , and the right side corresponding to the "like extremely" was given the value of 9. All the sessions were conducted in a climate-controlled sensory analysis laboratory equipped with individual booths.

The samples of functional drink, containing SPI and inulin, manufactured industrially were supplied to the Medical
Faculty of Vilnius University for medical nutrition experiments.

\section{Medical study design}

Volunteers were $23.5 \pm 5.5$ years of age. All subjects modified their diet by $500 \mathrm{~mL}$ of functional drink consumed daily over a period of 21 days (inulin $10 \mathrm{~g} /$ day, soy protein $20 \mathrm{~g}$ / day); at the same time they were encouraged not to change their dietary habits. The volunteers were invited to arrive at the hospital between 7:30 a.m. and 9:00 a.m. after having fasted for $12 \mathrm{~h}$. A blood sample was taken on the first visit before the dose of functional drink had been consumed and on the second visit after the last dose of the functional drink was consumed (on the 21st day).

The study was approved by the Lithuanian Bioethics Committee (2012-11-29; Order No. 158200-12-227-158).

\section{Medical study methods}

Cholesterol and triglyceride concentrations in serum were analyzed by enzymatic colorimetric methods (Architect ci8200, Abbott, Chicago, USA). LDL-cholesterol concentration was calculated using the Friedewald formula. High density lipoproteins (HDL) cholesterol was analyzed by the accelerator selective detergent method (Architect ci8200, Abbott, Chicago, USA). Plasma glucose concentration was analyzed by the hexokinase enzymatic method (Architect ci8200, Abbott, Chicago, USA). The serum insulin was measured by chemiluminescent microparticle immunoassay (Architect ci8200, Abbott, Chicago, USA). The oxidized LDL in plasma was detected by the ELISA (Mercodia, Uppsala, Sweden) based on the direct sandwich technique in which monoclonal antibodies are directed against separate antigenic determinants on the oxidized apolipoprotein B molecule. Fibrinogen concentration was analyzed in blood plasma by the Clauss coagulometric method (STA-Compact, Diagnostica Stago, Paris, France). C-reactive protein (CRP) in blood serum was measured by the latex immune turbidimetry method (Architect ci8200, Abbott, Chicago, USA).

Different faecal microbiota compositions were examined: pathogenic and conditionally pathogenic (Yersinia enterocolitica, non-lactose fermenting E.coli, hemolytic E.coli, species of Klebsiella, Enterobacter, Citrobacter and Staphylococcus aureus, fungus Clostridium and others) and non-pathogenic microorganisms (normal E.coli, species of Enterococcus, bifidobacterium, lactobacterium, bacteroides).

Different methods for the calculation/estimation and identification of faecal microorganisms were used: calculation of bacterial colonies (Enterobacteriaceae and Enterococcus, anaerobic bacteria); manual biochemical identification tests and also the Remel ERIC Rapid ONE system were used for identification of pathogenic bacterium and Enterobacteriaceae; VITEK 2 Compact system for Campylobacter, for non-fermenting bacteria and other microorganisms; agglutination test for Salmonella and Shigella species; agar with vancomycin, metronidazole, kanamycin and colistin disks for bacteroides and Clostridium species; microscopy methods for bifidobacterium, lactobacterium microorganisms; agar of Saburo for fungi, assessment of typical colonies and the production of lecitinase for Staphylococcus aureus, in case of some doubt Staphylococcus aureus antiserum was used. 


\section{Statistical analysis}

The statistical analysis was performed using the SPSS (Statistics Base 19.0). Dependent t-test for paired samples was carried out to examine the differences between the baseline and 21-day follow-up results. The significance level of $\alpha=0.05$ was used for all the analyses.

\section{RESULTS AND DISCUSSION}

\section{Results of the technological experiments}

Active acidity of drinks is the important parameter that determines the sensory properties, microbiological safety and stability during storage. The $\mathrm{pH}$ of fresh bio drink prepared with SPI and inulin was $6.87 \pm 0.04$. After 30 days of storing the samples at $4 \pm 2{ }^{\circ} \mathrm{C}$, a tendency of a slight increase of this parameter of the sample was observed: $\mathrm{pH}$ increased to $7.00 \pm 0.02$.

It should be noted that during the sedimentation studies, the formation of sediments was not recorded neither in the fresh drink samples nor in the samples after 30 days of storage. This can be related to a significant decrease in the particle size of the drink after homogenization (results not shown), and possibly after sterilization, as we have failed to produce drink stable to sedimentation when only pasteurization procedure was applied. The impact of homogenization on the reduction of particle size in the drinks has also been confirmed by other authors [Betoret et al., 2009].

Having evaluated the microbiological indicators of the beverages, it was found that they are in compliance with the requirements of the Commission Regulation (EC) No. 2073/2005. In the tested samples, the total number of microorganisms, coliforms and Escherichia coli in all the cases of the experiments (both after manufacture on the first day of storage, as well as keeping the drinks for 30 days) was less than $1.0 \times 10^{1} \mathrm{CFU} / \mathrm{g}$. This indicates the safety of the manufactured products and the suitability for consumption for 30 days from the date of manufacture, keeping the drinks at $4 \pm 2{ }^{\circ} \mathrm{C}$.

In particular, it was important to produce a drink, acceptable for the consumer, with sensory properties which would remain unchanged during storage. Mean consumer ratings of sensory attributes are shown in Table 1. It can be noted that the majority of the respondents liked the product and the product did not receive any negative ratings with regard to its odour, taste or appearance. The consistency of the product was evaluated as less acceptable than other sensory properties because the consumers noted the unusual thickness in the mouth and a certain coating of the mouth which remained after the product. The evaluated sensory properties had a mean rating between 7 and 8, which corresponds to the "like slightly" and "like much" points respectively, and shows that the product was acceptable for the consumers.

\section{Results of medical examination}

The data of lipids, carbohydrates, oxidized LDL and other measurements of the group of volunteers before and after diet supplementation by functional drink are summarized in Table 2. It can be noticed that no significant differences in cholesterol, triglycerides, fibrinogen, CRP, insulin and glu-
TABLE 1. Sensory properties of drink enriched with soy protein isolate and inulin during storage at $4^{\circ} \mathrm{C}$.

\begin{tabular}{lcccc}
\hline Acceptability & After 1 day & After 30 days & $\mathrm{p}$ \\
\hline Appearance & 7.96 & 7.30 & 0.589 \\
Odour & 7.65 & 7.63 & 0.458 \\
Taste & 7.66 & 7.60 & 0.144 \\
Consistency & 7.08 & 7.50 & 0.356 \\
Overall & 7.97 & 7.65 & 0.482 \\
\hline
\end{tabular}

TABLE 2. Serum levels of lipids, carbohydrates and other biochemical characteristics of the group of volunteers before and after diet supplementation with the functional drink $(n=30)$.

\begin{tabular}{lcccc}
\hline Blood characteristics & Before & After & $\mathrm{p}$ \\
\hline Total cholesterol (mmol/L) & $4.71 \pm 0.75$ & $4.65 \pm 0.62$ & 0.574 \\
HDL-cholesterol (mmol/L) & $1.51 \pm 0.29$ & $1.52 \pm 0.31$ & 0.668 \\
LDL-cholesterol (mmol/L) & $2.73 \pm 0.71$ & $2.72 \pm 0.62$ & 0.466 \\
Triglycerides (mmol/L) & $0.92 \pm 0.49$ & $0.87 \pm 0.37$ & 0.330 \\
OxLDL (U/L) & $55.37 \pm 28.02$ & $45.73 \pm 16.58$ & $0.016^{*}$ \\
Insulin (pmol/L) & $66.50 \pm 36.53$ & $64.38 \pm 46.19$ & 0.466 \\
Fasting glucose (mmol/L) & $5.03 \pm 0.34$ & $5.10 \pm 0.35$ & 0.203 \\
Fibrinogen (g/L) & $3.07 \pm 0.71$ & $3.09 \pm 0.53$ & 0.637 \\
CRP (mg/L) & $1.15 \pm 1.80$ & $0.65 \pm 0.45$ & 0.821 \\
\hline
\end{tabular}

HDL - high density lipoprotein; LDL - low density lipoprotein; OxLDL - oxidized low density lipoproteins; CRP-C-reactive protein, ${ }^{*} \mathrm{p}<0.05$.

cose concentrations were observed among the young volunteers before and after the consumption of functional drink.

Our study showed that administration of the bio drink, enriched with SPI and, inulin had no effect on blood lipid parameters - the total cholesterol, HDL-cholesterol, LDL-cholesterol and triacylglycerol remained unchanged (Table 2). Other researchers also did not find a significant effect of inulin on lipid and carbohydrate metabolism [Causey et al., 2000; Letexier et al., 2003]. However, there are scientific studies that demonstrated a positive impact of soy protein on lipid metabolism [Zhan \& Ho, 2005]. We consider that the absence of statistically significant change in lipid parameters may be due to young and healthy subjects with normal blood lipid concentrations. Such individuals may have a strong compensatory mechanism to maintain normal metabolism and blood biochemical indicators within the normal range. In our earlier studies performed with patients we stated that yogurt enriched with inulin had a positive effect on lipids metabolism: decreased LDL-cholesterol levels in the blood plasma of patients with metabolic syndrome [Kaminskas et al., 2013].

Some authors have observed the anti-inflammatory effect of soy protein [Burris et al., 2014]. Nevertheless, no significant differences in acute phase proteins, especially C-reactive protein had been established in our study. It is clear that the antiinflammatory effect of soy components can be very important 
TABLE 3. Intestinal pathogenic or conditionally pathogenic microorganisms of volunteers before and after drink supplementation. The results are presented as the number of persons in the group of volunteers $(n=30)$ which exceeded the recommended intestinal microflora values.

\begin{tabular}{|c|c|c|}
\hline Microorganisms & Before (CFU/1 g) & After $(\mathrm{CFU} / 1 \mathrm{~g})$ \\
\hline $\begin{array}{l}\text { Pathogenic intestinal } \\
\text { microorganisms }\end{array}$ & 0 & 0 \\
\hline $\begin{array}{l}\text { Non-lactose fermenting } \\
\text { Escherichia coli }\end{array}$ & 2 persons & 3 persons \\
\hline Hemolytic Escherichia coli & 5 persons & 3 persons* \\
\hline \multirow{12}{*}{$\begin{array}{l}\text { Opportunistic pathogenic } \\
\text { enterobacteria }\end{array}$} & \multicolumn{2}{|c|}{ species of Klebsiella: } \\
\hline & 1 person & 5 persons* \\
\hline & \multicolumn{2}{|c|}{ species of Enterobacteria: } \\
\hline & 2 persons & 3 persons \\
\hline & \multicolumn{2}{|c|}{ species of Citrobacteria: } \\
\hline & 10 persons & 7 persons \\
\hline & \multicolumn{2}{|c|}{ species of Serratia: } \\
\hline & 1 person & 0 \\
\hline & \multicolumn{2}{|c|}{ species of Proteus: } \\
\hline & 1 person & 0 \\
\hline & \multicolumn{2}{|c|}{$\begin{array}{c}\text { non fermenting bacteria } \\
\text { (Sphingomonas paucimobilis): }\end{array}$} \\
\hline & 1 person & 1 person \\
\hline Staphylococcus aureus & 0 & 1 person \\
\hline Yeast & 12 persons & 7 persons \\
\hline Clostridium & 3 persons & 4 persons \\
\hline
\end{tabular}

$* \mathrm{p}<0.05$.

for the prevention of chronic inflammatory diseases such as atherosclerosis. In another study, a positive effect of soy protein on insulin metabolism and also optimal glucose concentration was demonstrated [Ascencio et al., 2004]. Our study did not show any statistically significant change of insulin as well as glucose concentration after 3 weeks of consumption of the bio-drink.

In our study, the individuals showed a significant decrease of the oxidized LDL $(55.37 \pm 28.02 \mathrm{U} / \mathrm{mL}$ vs. $45.73 \pm 16.58 \mathrm{U} /$ $\mathrm{mL})(\mathrm{p}=0.016)$ after 21-day period of consumption of these products. Many forms of stress can alter the health and outlook on life through the oxidative damage. The oxidative injury has been implicated in a number of chronic health conditions. Therefore, it is important to consume adequate amounts of dietary antioxidants to reduce the oxidative stress and maintain overall health. A growing amount of scientific research suggest that the isoflavones in soy are powerful antioxidants. Several clinical studies have demonstrated the beneficial antioxidant effects of soy. It was reported that soy isoflavones reduce the markers of oxidative damage and improve the total antioxidant status [Bazzoli et al., 2002; Chen et al., 2005]. The scientific research has also suggested the antioxidant effect of inulin and indicated that inulin protects the human colon mucosa from lipopolysaccharide (LPS)-induced damage related to the protective effect of inu-
TABLE 4. Spectrum of intestinal non-pathogenic microorganisms (probiotics) of volunteers before and after drink supplementation. The results are presented as the number of persons in group of volunteers $(n=30)$ which had the recommended values of intestinal microflora below normal range.

\begin{tabular}{lcc}
\hline Microorganisms & Before $(\mathrm{CFU} / 1 \mathrm{~g})$ & After $(\mathrm{CFU} / 1 \mathrm{~g})$ \\
\hline Normal Escherichia coli & 2 persons & 2 persons \\
Enterococcus & 2 persons & $0^{*}$ \\
Bifidobacteria & 1 person & 1 person \\
Lactobacteria & 6 persons & 3 persons \\
Bacteroides & 0 & 1 person \\
$* \mathrm{p}<0.05$. &
\end{tabular}

lin against LPS-induced oxidative stress [Stoyanova et al., 2011; Van den Ende et al., 2011].

The results obtained in our study confirmed the significant antioxidant activity of soy-inulin products, so including these supplements in a daily diet can help to reduce the effects of everyday stress. According to these findings, the consumption of products enriched with soy protein and inulin might have a beneficial effect on patients and support better antioxidant status.

We have not identified pathogenic microorganisms in any of the investigated faecal samples before and after drink consumption (Table 3). After a 21-day period of diet supplementation with SPI (20 g/day) and inulin (10 g/day) the number of the hemolytic E.coli statistically significantly decreased $(\mathrm{P} \leq 0.05)$, however, the number of conditionally pathogenic Klebsiella bacterium increased $(\mathrm{P} \leq 0.05)$. In some of the investigated faeces lower numbers of Citrobacteria, Serratia, yeast and Proteus were recorded, but more non-lactose fermenting E.coli, Staphylococcus aureus, Enterobacteria, and Clostridium microorganisms were found. No statistically significant differences were found in other investigated faecal microorganisms (Table 4), except for the increase in the numbers of Enterococcus. Paßlack et al. [2015] also showed that dietary inulin supplementation (3\%) increased the numbers of enterococci, but it is contrary to other studies [Kleesen et al., 2007; Waitzberg et al., 2012].

\section{CONCLUSIONS}

Selection of appropriate parameters for drink with SPI $(4 \mathrm{~g} / 100 \mathrm{~g})$ and inulin $(2 \mathrm{~g} / 100 \mathrm{~g})$ manufacture: $\mathrm{pH}(6.8-7.0)$, homogenization (at $15 \mathrm{MPa}$ ) and sterilization (at $121^{\circ} \mathrm{C}$, $12 \mathrm{~min}$ ), ensured the physical stability, microbiological safety and high acceptability scores of bio drink during 30 days of storage at $4 \pm 2{ }^{\circ} \mathrm{C}$.

The study showed that the consumption of the bio drink, enriched with soy protein-inulin preparations, for 21 days had no effect on lipid metabolism parameters, glucose, insulin, an acute phase protein level in healthy, normal body weight subjects as compared with their baseline (before consumption of drink) tests.

The evaluation of the concentration of oxidized LDL showed that the drink had an antioxidant effect: the level of oxidized LDL significantly decreased from $55.37 \pm 28.02 \mathrm{U} / \mathrm{L}$ to 
45.73 $\pm 16.58 \mathrm{U} / \mathrm{L}$ as compared with baseline characteristic $(P<0.05)$.

The spectrum of most examined faecal microorganism groups did not change significantly after 21-day period of consumption of the drink with SPI (20 g/day) and inulin (10 g/day), except for the reduction of hemolytic E. coli and increasing of conditionally pathogenic Klebsiella.

\section{ACKNOWLEDGEMENTS}

This research was funded by a grant No. SVE-08/2012 BIOGERIMAI from the Research Council of Lithuania.

\section{REFERENCES}

1. Ascencio C., Torres N., Isoard-Acosta F., Gomez-Perez F.J., Hernandez-Pando R., Tovar A.R., Soy protein affects serum insulin and hepatic SREBP-1 mRNA and reduces fatty liver in rats. J. Nutr., 2004, 134, 522-529.

2. Bazzoli D.L., Hill S., DiSilvestro R. A., Soy protein antioxidant actions in active, young adult women. Nutr. Res., 2002, 22, 807-815 .

3. Betoret E., Betoret N., Carbonell J.V., Fito P., Effect of pressure homogenization on particle size and the functional properties of citrus juices. J. Food Eng., 2009, 92, 18-23.

4. Burris R.L., Ng H.P., Nagarajan S., Soy protein inhibits inflammation-induced VCAM-1 and inflammatory cytokine induction by inhibiting the NF-кB and AKT signaling pathway in apolipoprotein E-deficient mice. Eur. J. Nutr., 2014, 53, 135-148.

5. Causey J.L., Feirtag J.M., Gallaher D.D., Tungland B.C., Slavin J.L., Effects of dietary inulin on serum lipids, blood glucose and gastrointestinal environment in hypercholesterolemic men. Nutr. Res., 2000, 20, 191-201.

6. Chen C.Y., Bakhiet R.M., Hart V., Holtzman G., Isoflavones improve plasma homocysteine status and antioxidant defense system in healthy young men at rest but do not ameliorate oxidative stress induced by $80 \%$ VO2pk exercise. Ann. Nutr. Metab., 2005, 49, 33-41.

7. Commission Regulation (EC) No. 2073/2005 of 15 November 2005 on microbiological criteria for foodstuffs.

8. EFSA Scientific Opinion on the substantiation of a health claim related to isolated soy protein and reduction of blood LDL-cholesterol concentrations pursuant to Article 14 of Regulation (EC) No 1924/2006. EFSA Journal, 2012, 10(2):2555, p. 17.

9. Gibson G.R., Dietary modulation of the human gut microflora using the prebiotics oligofructose and inulin. J. Nutr., 1999, 129, 1438S-1441.

10. Hoie L.H., Guldstrand M., Sjoholm A., Graubaum H.J., Gruenwald J., Zunft H.J., Lueder W., Cholesterol-lowering effects of a new isolated soy protein with high levels of nondenaturated protein in hypercholesterolemic patients. Adv. Ther., 2007, 24, 439-447.

11. ISO 4833-1:2013 Microbiology of the food chain - Horizontal method for the enumeration of microorganisms - Part 1: Colony count at 30 degrees $\mathrm{C}$ by the pour plate technique.

12. ISO 4832:2006 Microbiology of food and animal feeding stuffs - Horizontal method for the enumeration of coliforms - Colonycount technique.

13. ISO 16649-2:2001 Microbiology of food and animal feeding stuffs - Horizontal method for the enumeration of beta-gluc- uronidase-positive Escherichia coli - Part 2: Colony-count technique at 44 degrees $\mathrm{C}$ using 5-bromo-4-chloro-3-indolyl beta-D-glucuronide.

14. Kaminskas A., Abaravičius J.A., Liutkevičius A., Jablonskienė V., Valiūnienė J., Bagdonaitė L., Andrikonytė J., Hendrixson V., Sekmokienė D., Quality of yoghurt enriched by inulin and its influence on human metabolic syndrome. Vet. Med. Zoot., 2013, $64,23-28$.

15. Kleessen B., Schwarz S., Boehm A., Fuhrmann H., Richter A., Henle T., Krueger M., Jerusalem artichoke and chicory inulin in bakery products affect faecal microbiota of healthy volunteers. Brit. J. Nutr., 2007, 98, 540-549.

16. Kuntz M.G.F., Fiates G.M.R., TeIxeira E., Characteristics of prebiotic food products containing inulin. Brit. Food J., 2013, 115, 235-251.

17. Letexier D., Diraison F., Beylot M., Addition of inulin to a moderately high-carbohydrate diet reduces hepatic lipogenesis and plasma triacylglycerol concentrations in humans. Am. J. Clin. Nutr., 2003, 77, 559-564.

18. Lindeberg S., Food and western disease: health and nutrition from an evolutionary perspective. 2013, (2. Expending our perspective, pp. 8-29). Wiley-Blackwell, Kindle Edition, p. 368.

19. Paßlack N., VahjenW., Zentek J., Dietary inulin affects the intestinal microbiota in sows and their suckling piglets. BMC Vet. Res., 2015, 11, 351.

20. Pang G.C., Xie J., Chen Q., Hu Z., How functional foods play critical roles in human health. Food Sci. Hum. Wellness, 2012, 1, 26-60.

21. Schaafsma G.J., The protein digestibility-corrected amino acid score. J. Nutr., 2000, 130, 1865-1867.

22. Stoyanova S., Geuns J., Hideg E., Van Den Ende W., The food additives inulin and stevioside counteract oxidative stress. Int. J. Food Sci. Nutr., 2011, 62, 207-214.

23. Thorp A.A., Howe P.R., Mori T.A., Coates A.M., Buckley J.D., Hodgson J., Mansour J., Meyer B.J., Soy food consumption does not lower LDL cholesterol in either equol or nonequol producers. Am. J. Clin. Nutr., 2008, 88, 298-304.

24. Tsumura K., Saito T., Tsuge K., Ashida H., Kugimiya W., Inouye K., Functional properties of soy protein hydrolysates obtained by selective proteolysis. LWT-Food Sci. Tech., 2005, 38, 255-261.

25. Van den Ende W., Peshev D., De Gara L., Disease prevention by natural antioxidants and prebiotics as ROS scavengers in the gastro-intestinal tract. Trends Food Sci. Tech., 2011, 22, 689-697.

26. Waitzberg L.D., Alves Pereira C.C., Logullo L., Manzoni Jacintho T., Almeida D., Teixeira da Silva M.L., Matos de Miranda Torrinhas R.S., Microbiota benefits after inulin and partially hydrolyzed guar gum supplementation: a randomized clinical trial in constipated women. Nutr. Hosp., 2012, 27, 123-129.

27. WHO, Strategy on Diet, Physical Activity and Health, 2004. [http://apps.who.int/iris/bitstream/10665/43035/1/9241592222_ eng.pdf?ua $=1]$.

28. Xiao C.W., Health effects of soy protein and isoflavones in humans. J. Nutr., 2008, 138, 1245s-1249s.

29. Zhan S., Ho S.C., Meta-analysis of the effects of soy protein containing isoflavones on the lipid profile. Am. J. Clin. Nutr., 2005, 81, 397-408.

Submitted: 29 June 2015. Revised: 4 July and 9 October 2015. Accepted: 7 December 2015. Published on-line: 21 January 2016. 
